\title{
Maternally inherited diabetes and deafness complicated by mesangial galactose- deficient lgA1 deposits: a case report
}

Keiji Sugai ${ }^{1}$, Hiroyuki Ueda ${ }^{1 *}$ D, Keita Morimoto ${ }^{1}$, Mai Tanaka ${ }^{1}$, Daisuke Takahashi ${ }^{1}$, Akio Nakashima', Junichiro Kato ${ }^{1}$, Hiroshi Takahashi ${ }^{2}$, Yutaka Yamaguchi ${ }^{3}$, Tetsuya Kawamura ${ }^{1}$, Kazushige Hanaoka', Yoichi Miyazaki ${ }^{1}$ and Takashi Yokoo ${ }^{1}$

\begin{abstract}
Background: Maternally inherited diabetes and deafness (MIDD), a mitochondrial genetic disorder, typically affects the kidneys and results in end-stage renal disease. Early diagnosis of MIDD is challenging when renal manifestations precede other key clinical features such as diabetes and deafness and/or when the disease is complicated by other renal pathologies.

Case presentation: Here, we present the case of a 33-year-old Japanese woman who had initially been diagnosed with IgA nephropathy but was found to have MIDD 6 years later. Two renal biopsies were conducted six years apart. While assessment of the first biopsy specimen with the monoclonal antibody (KM55) revealed mesangial IgA deposits (containing the galactose-deficient IgA1 variant [Gd-IgA1]), examination of the second specimen showed no mesangial IgA deposits and newly-developed glomerular global scleroses and tubular damage. Granular swollen epithelial cells (GSECS), characterised by abnormal mitochondria, were observed among the tubules and collecting ducts in both biopsy specimens. Mitochondrial DNA analysis revealed an m.3243A > G mutation.

Conclusions: We rediscovered the usefulness of GSECS as a pathologically distinctive feature of mitochondrial nephropathy and reviewed the literature regarding MIDD complicated by mesangial IgA deposition. Furthermore, we demonstrate that the mesangial IgA deposits in this patient consisted of the galactose-deficient IgA1 variant. The monoclonal antibody (KM55) might be a useful tool to distinguish IgAN from latent IgA deposits.
\end{abstract}

Keywords: Maternally inherited diabetes and deafness, IgA deposits, Kidney disease, Case report, Galactose-deficient IgA1 variant

\section{Background}

Maternally inherited diabetes and deafness (MIDD) result from genetic abnormalities in mitochondrial DNA, with an A to G substitution at position 3243 (m.3243A > G) being the most common point mutation [1]. Kidneys are susceptible to mitochondrial dysfunction, and MIDD patients have a high incidence of end-stage renal disease. The prevalence of MIDD is high in Japan, and MIDD accounts for 0.9 to $5.9 \%$ of patients with diabetes who receive dialysis [2, 3].

\footnotetext{
* Correspondence: hi-ro@jikei.ac.jp

${ }^{1}$ Division of Nephrology and Hypertension, Department of Internal Medicine,

The Jikei University School of Medicine, Tokyo, Japan

Full list of author information is available at the end of the article
}

Immunoglobulin (Ig)A nephropathy (IgAN) is the most common cause of glomerulonephritis worldwide. Previous multi-ethnic genome-wide association studies have identified risk loci resulting in a predisposition to IgAN [4-7]. Furthermore, although IgAN is prevalent worldwide, Japanese individuals carry a genetic predisposition to IgAN [6]. Therefore, nephrologists could encounter patients with MIDD, which is complicated by IgAN. However, diagnosing MIDD in patients with IgAN is challenging, particularly when renal manifestations precede diabetes or deafness. Here, we demonstrate the clinical and histological course of MIDD, complicated by IgAN, through repeated renal biopsies.

C The Author(s). 2018 Open Access This article is distributed under the terms of the Creative Commons Attribution 4.0 International License (http://creativecommons.org/licenses/by/4.0/), which permits unrestricted use, distribution, and 


\section{Case presentation}

A 33-year-old Japanese woman with a history of IgAN and diabetes mellitus was admitted to our hospital for the initiation of insulin therapy and evaluation of persistent proteinuria in 2015.

She had undergone a renal biopsy for proteinuria and had been diagnosed with IgAN at our hospital in 2009. At the current presentation, she had $0.7-1.0 \mathrm{~g} /$ day of urinary protein excretion without significant haematuria. Although her mean blood pressure was $110 / 60 \mathrm{mmHg}$, she was treated with an angiotensin receptor blocker (ARB) for IgAN with persistent proteinuria. Her urinary protein excretion levels had been about $0.5 \mathrm{~g} /$ day after the initiation of ARB. Two years later, a tonsillectomy for persistent proteinuria was performed. The patient was diagnosed with diabetes mellitus based on the fasting plasma glucose levels and haemoglobin A1c (HbA1c) levels during regular visits and was started on a dipeptidyl peptidase-4 (DPP-4) inhibitor and Pioglitazone in 2012. One year later, she discontinued both the regular visits to our hospital and her medication. Seven days prior to admission at our hospital, she visited a clinic for fatigue. Her random blood glucose level was $375 \mathrm{mg} / \mathrm{dL}$; based on this result and persistent proteinuria, she was referred to our hospital.

Regarding her family history, her younger sister was diagnosed with impaired glucose tolerance, while her maternal grandmother was diagnosed with diabetes (Fig. 1). The physical examination was unremarkable; she had a height of $147.0 \mathrm{~cm}$ and weight of $46 \mathrm{~kg}$ (body mass index [BMI] 21.3). Laboratory testing revealed several abnormal values, including a random blood glucose level of $355 \mathrm{mg} / \mathrm{dL}$, HbA1c level of $10.8 \%$, $95 \mathrm{mmol} / \mathrm{mol}$ (reference; $4.6-6.2 \%, 27-44 \mathrm{mmol} / \mathrm{mol}$ ), lactic acid level of $19.4 \mathrm{mg} / \mathrm{dL}$ (reference, $3.0-17.0 \mathrm{mg} / \mathrm{dL}$ ), and pyruvic acid level of $1.28 \mathrm{mg} / \mathrm{dL}$ (reference, $0.30-0.94 \mathrm{mg} / \mathrm{dL}$ ). Her renal function was preserved, as her creatinine

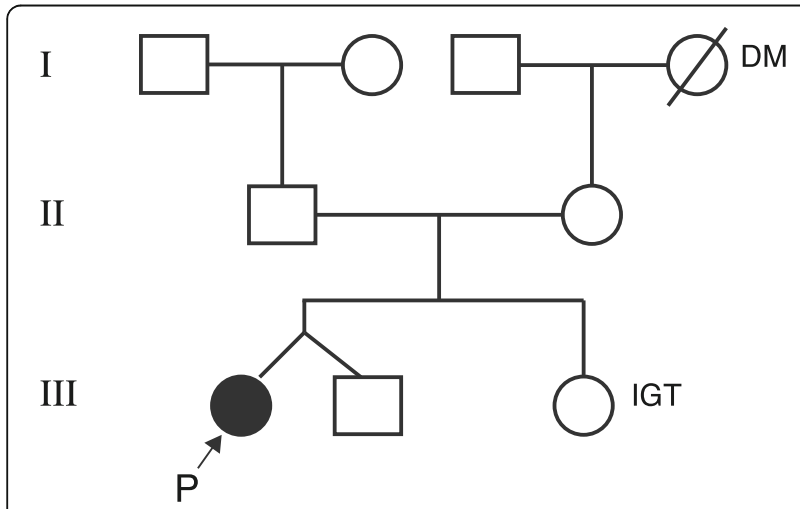

Fig. 1 Family tree. The patient's younger sister had impaired glucose tolerance, and her maternal grandmother was diagnosed with diabetes mellitus. DM, diabetes mellitus; IGT, impaired glucose tolerance; $P$, patient level was $0.52 \mathrm{mg} / \mathrm{dL}$ (reference, $0.47-0.79 \mathrm{mg} / \mathrm{dL}$ ) and her estimated glomerular filtration rate (eGFR) was $107.5 \mathrm{~mL} / \mathrm{min} / 1.73 \mathrm{~m}^{2}$. No antibodies to glutamic acid decarboxylase (GAD) or islet cells were detected. Urinalysis revealed $1+$ protein and 4+ glucose without blood by dipstick. A 24-h urine collection test showed a creatinine clearance $(\mathrm{CCr})$ of $175 \mathrm{~mL} / \mathrm{min}, 2.08 \mathrm{~g}$ of protein with poor selectivity, and C-peptide immunoreactivity (CPR) of $33.3 \mu \mathrm{g}$ (reference, 29.2-167 $\mu \mathrm{g}$ ). During closer evaluation, the patient recalled having a hearing impairment during her school days. Therefore, audiometry was conducted and revealed mild bilateral sensorineural hearing loss $>4$ $\mathrm{kHz}$. Electrocardiography and echocardiography showed no abnormalities. No diabetic changes or macular retinal dystrophy were observed on funduscopic examinations.

Based on the above findings, we suspected mitochondrial disease. A second percutaneous renal biopsy was performed to identify the cause of the persistent proteinuria in 2015 (Fig. 2d-f). The biopsy specimens for light microscopy contained 25 glomeruli, of which 6 were globally sclerotic. The remaining glomeruli revealed no mesangial hypercellularity or expansion of the matrix (Fig. 2d). There was no evidence of thickness of the glomerular basement membranes, crescents, necrotising lesions, or lesions of focal segmental sclerosis. Moderate tubular atrophy and interstitial fibrosis involving up to 30 to $40 \%$ of the sample were observed (Fig. 2e). Abnormally distended epithelial cells containing numerous small intracytoplasmic granules that were positive for periodic acid-Schiff staining were present among the collecting ducts (Fig. 2f, arrowhead). These cells were identical to 'granular swollen epithelial cells (GSECs)', which have previously been reported as a morphologic feature of mitochondrial nephropathy. Immunofluorescence staining for IgA and C3 was negative (Fig. 3d). On ultrastructural examination, no significant deposits were observed in the glomeruli (Fig. 4b). Podocyte foot processes were globally preserved. No cell type with an abnormal shaped or increased number of mitochondria was observed either in the glomeruli or the tubules. The GSECs that had been observed in the microscopic analysis were not apparent in the specimen for electron microscopy.

A review of the first renal biopsy specimen (Fig. 2a-c) revealed the presence of 12 glomeruli; of these, none were globally sclerosed (Fig. 2b). The glomeruli exhibited mild mesangial widening accompanied by IgA deposition (Figs. 2a, 3a, and 4a), but no crescents, mesangial hypercellularity, or segmental sclerosis. These findings correspond to M0, E0, S0, T0, and C0 in the Oxford-MEST-C classification of IgA nephropathy [8]. IgG was negative, and C3 was dimly positive on immunohistology (data not shown). We stained the first biopsy specimen with a monoclonal antibody (KM55) against Gd-IgA1 (IBL, Gunma, Japan) [9]; this immunofluorescence analysis 

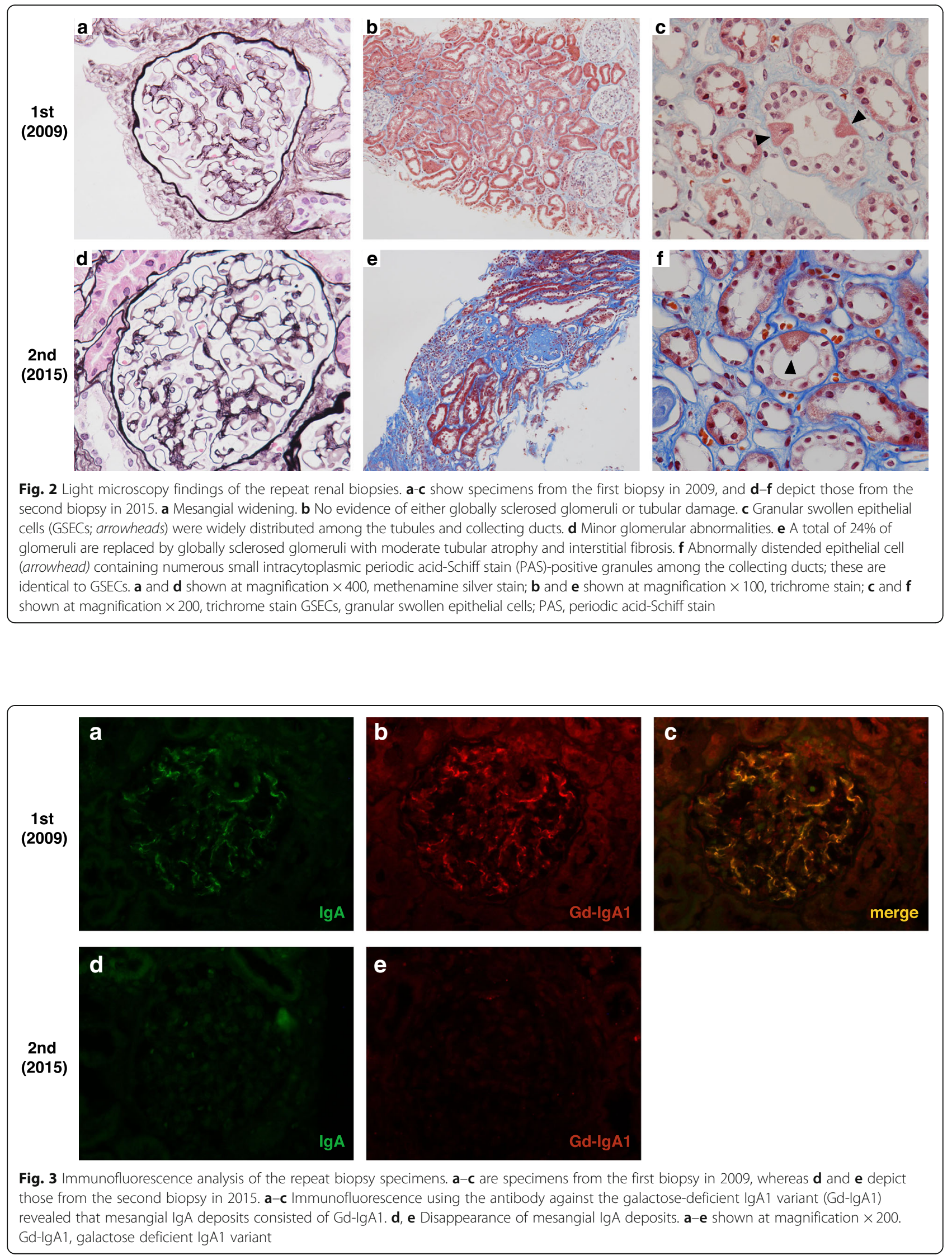

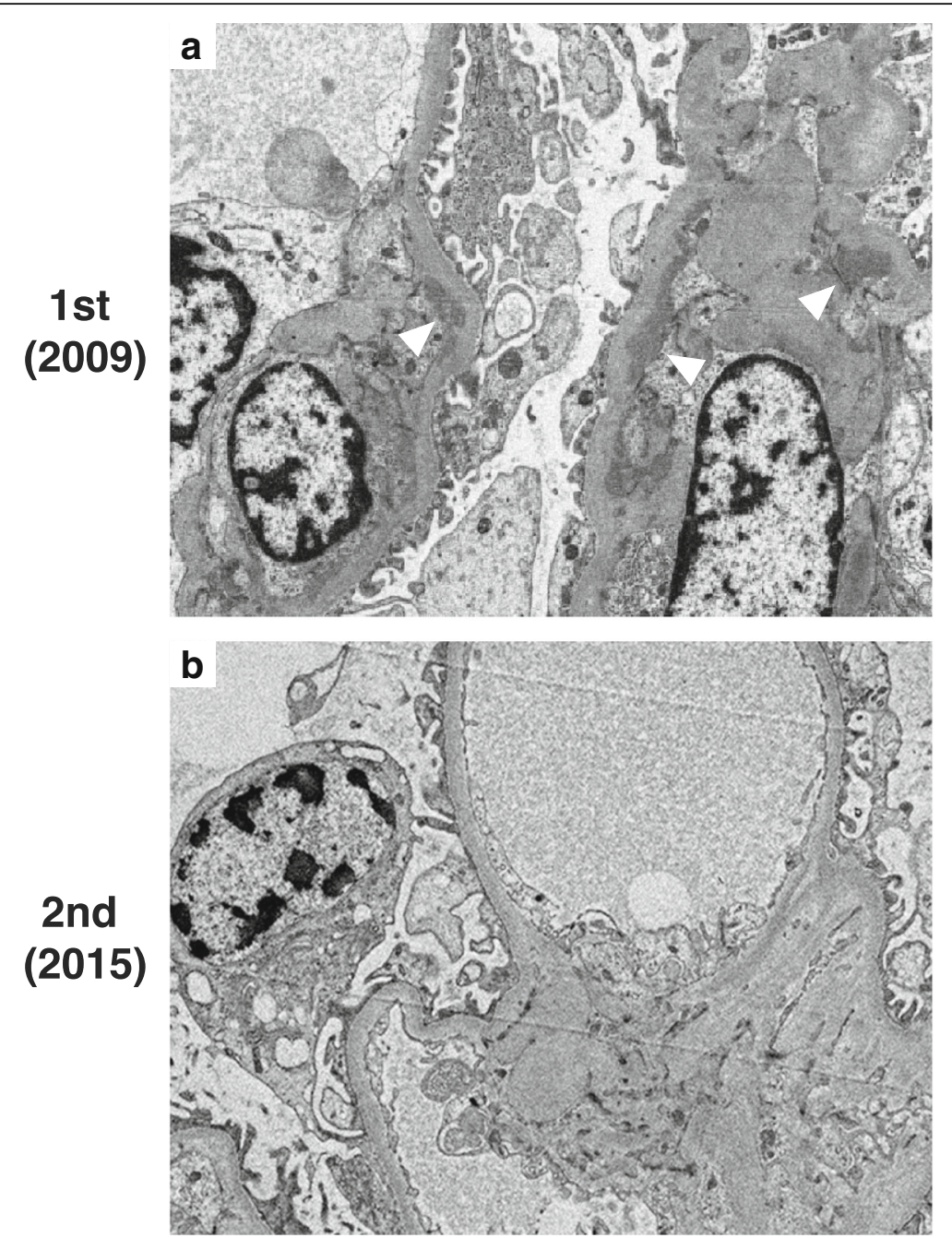

Fig. 4 Electron microscopy of the repeat biopsy. $\mathbf{a}$ is a specimen from the first biopsy in 2009, and $\mathbf{b}$ depicts a specimen from the second biopsy in 2015. a Electron microscopy showing mesangial dense deposits at the first biopsy specimen (arrowheads). b Electron microscopy confirming the disappearance of mesangial IgA deposits in the second biopsy specimen. $\mathbf{a}$ and $\mathbf{b}$ shown at magnification $\times 6000$

revealed that the IgA1 deposits in the patient's glomeruli consisted of Gd-IgA1 (Fig. 3a-c). No tubular atrophy or interstitial fibrosis were evident (Fig. 2b); however, numerous GSECs were present among the distal tubules and collecting ducts (Fig. 2c, arrowheads). On electron microscopic analysis, cells containing dysmorphic mitochondria were not apparent in the glomeruli or tubules.

Mitochondrial DNA analysis from peripheral blood revealed a $\mathrm{m}$. DNA3243A > G mutation. Therefore, the patient was diagnosed with MIDD. After the initiation of insulin therapy, her blood glucose levels returned to a normal range, and she was discharged.

\section{Discussion}

Our case demonstrates the difficulties in diagnosing mitochondrial nephropathy during the early stages of the disease, especially when it is complicated by other glomerular diseases and lacks the clinical key features such as diabetes and deafness.

An A to G substitution at position 3243 (m.3243A > G) of mitochondrial DNA affects the mitochondrial tRNA ${ }^{\text {Leu }}$ tertiary structure and leads to defects in the activities of complexes 1 , and 4 of the respiratory chain within the mitochondria [10, 11]. Therefore, MIDD typically affects metabolically active organs such as the endocrine pancreas and cochlea, and in some cases, also the retina, muscles, kidneys, and brain. Renal manifestation sometimes precedes the diagnosis of either diabetes or deafness and can even be the sole manifestation of MIDD [12-14]. Proteinuria is a common presentation of the disease.

Focal segmental glomerular sclerotic (FSGS) lesions or tubular damage complicated by mitochondrial cytopathies are prevalent findings in the renal biopsy specimens of patients with MIDD. Electron microscopy 
findings of abundant and morphologically abnormal mitochondria in the cytoplasm can facilitate diagnosing mitochondrial nephropathy. However, heteroplasmy associated with mitochondrial DNA mutations often hampers the diagnosis of mitochondrial diseases through sampling errors.

The utility of GSECs for diagnosing MIDD was first described by Kobayashi et al. in 2010 who reported that GSECs were frequently observed in the collecting ducts or tubules of the kidneys of patients with MIDD [15]. The ultrastructure of GSECs is defined by abnormally shaped or increased numbers of mitochondria per cell. GSECs are observed not only in genetic mitochondrial disorders but also in miscellaneous conditions, including ageing, low birth weight, various drug toxicities, and heavy metal poisoning [16, 17]. In our case, neither FSGS lesions nor tubular damages were obvious in the first biopsy specimen. Mesangial widening and IgA deposition led us to diagnose the patient with IgAN at the time, as this also explained her persistent proteinuria. GSECs were observed in the collecting ducts in the first biopsy specimen, but the specimens for electron microscopy did not contain cells with abnormally shaped mitochondria; moreover, diabetes and deafness were not evident at the time. Six years after her initial renal biopsy, the patient underwent a second biopsy for persisting proteinuria. This second biopsy revealed a disappearance of mesangial IgA deposits with increasing numbers of global scleroses. No FSGS lesions were evident. Moderate tubular damage was observed, and there were fewer GSECs when compared to the first biopsy. The disappearance of IgA deposits in patients with IgAN has been occasionally observed after immunosuppressive treatment alone, or with tonsillectomy [18-20]. The patient in our case had undergone renin-angiotensin system (RAS) blockade therapy and tonsillectomy. Several recent studies reported that patients with IgAN had significantly higher levels of serum IgA1 levels with galactose-deficient $O$-linked glycan moieties in the hinge region (Gd-IgA1) when compared to healthy individuals. Furthermore, Gd-IgA1 has been reported to be the predominant variant of IgA1 in the mesangium of patients with $\operatorname{IgAN}[21,22]$. Using a newly developed antibody, we also confirmed that the IgA deposits in our patient contained Gd-IgA1 [9]. The origin of Gd-IgA1 has yet to be determined, but some reports suggested that the mucosal immune systems, including the tonsils, are a potential source of Gd-IgA1 $[23,24]$. In this report, we could not address how serum Gd-IgA1 levels of our patient changed after tonsillectomy due to a lack of serum sample at the first biopsy. Further studies are needed to clarify whether tonsillectomy can contribute to a decrease in Gd-IgA1 production and its disappearance from the glomeruli.
In a literature search, we found four case reports (three from Japan) of mitochondrial nephropathy complicated by glomerular IgA deposition [25-28]. All patients underwent renal biopsies for persistent proteinuria before a diagnosis of mitochondrial disease was made. According to previous studies, IgA deposition was observed in 4 to $10 \%$ of consecutive necropsies without clinical evidence of renal disease [29-31] and 10 to 30\% of renal allografts at transplantation [32-34]. Therefore, IgA deposition can occur in the general population without clinical signs of renal disease. All previous cases discussed the possibility of mitochondrial nephropathies being accompanied by IgA deposits. It is difficult to clearly differentiate latent IgA deposits from IgAN when the condition is complicated by other renal pathologies. Haematuria or histological findings such as mesangial cell proliferation or $\mathrm{C} 3$ deposition might be helpful to distinguish between the two conditions. In our case, haematuria was negative, and the pathological changes were not severe enough to explain the cause of proteinuria at the first biopsy. However, our immunofluorescence analysis using the anti-Gd-IgA1 antibody supported the possibility of an IgAN diagnosis.

\section{Conclusions}

In this case, we illustrate the clinical and histological course of MIDD complicated by IgAN through repeated renal biopsies. Moreover, using a newly developed antibody against Gd-IgA1 revealed that the mesangial IgA deposits consisted of Gd-IgA1. This antibody might be useful to distinguish IgAN from latent IgA deposits.

\section{Abbreviations \\ ARB: Angiotensin receptor blocker; BMI: Body mass index; CC: Creatinine clearance; CPR: C-peptide immunoreactivity; DPP-4: Dipeptidyl peptidase-4; eGFR: Estimated glomerular filtration rate; FSGS: Focal segmental glomerular sclerotic; GAD: Glutamic acid decarboxylase; Gd-lgA1: galactose-deficient IgA1; GSECs: Granular swollen epithelial cells; HbA1c: Haemoglobin A1c; IgAN: Immunoglobulin (Ig)A nephropathy; MIDD: Maternally inherited diabetes and deafness; RAS: Renin-angiotensin system}

\section{Acknowledgements}

We sincerely thank Ms. Ishida Moeno for the outstanding technical support in immunofluorescence staining of the kidney specimens of the patient.

\section{Funding}

None.

Availability of data and materials

All data and material were presented in this manuscript.

\section{Authors' contributions}

$\mathrm{KS}$ and $\mathrm{HU}$ wrote the manuscript, and treated the patient. $\mathrm{KJ}$ and HS also treated the patient. $Y Y$ is a pathologist and the author of the reference [15]. We consulted him for the pathological interpretation of the patient. KM, MT, DT, AN, TK, KH, YM and TY assisted in diagnosing the patient and drafting the manuscript. All authors read and approved the final manuscript. 


\section{Ethics approval and consent to participate}

All procedures in this study were performed in accordance with the ethical standards of The Jikei University School of Medicine ethics and research committee. This study was not defined as a research study according to 'Ethical Guidelines for Medical and Health Research Involving Human Subjects' issued by Ministry of Health, Labor and Welfare of Japan, and therefore, submission of such studies to an ethics committee is not required.

\section{Consent for publication}

Written informed consent was obtained from the patient for publication of this case report and the images in it.

\section{Competing interests}

The authors declare that they have no competing interests.

\section{Publisher's Note}

Springer Nature remains neutral with regard to jurisdictional claims in published maps and institutional affiliations.

\section{Author details}

'Division of Nephrology and Hypertension, Department of Internal Medicine, The Jikei University School of Medicine, Tokyo, Japan. ${ }^{2}$ Division of Diabetes, Metabolism and Endocrinology, Department of Internal Medicine, The Jikei University School of Medicine, Tokyo, Japan. ${ }^{3}$ Yamaguchi's Pathology Laboratory, Chiba, Japan.

Received: 31 July 2017 Accepted: 23 November 2018 Published online: 10 December 2018

\section{References}

1. Maassen JA, Janssen GM, t Hart LM. Molecular mechanisms of mitochondrial diabetes (MIDD). Ann Med 2005;37:213-221. doi:https://doi. org/10.1080/07853890510007188

2. Iwasaki N, Babazono T, Tsuchiya K, Tomonaga O, Suzuki A, Togashi M, et al. Prevalence of A-to-G mutation at nucleotide 3243 of the mitochondrial tRNA(Leu(UUR)) gene in Japanese patients with diabetes mellitus and end stage renal disease. J Hum Genet. 2001;46:330-4. https://doi.org/10.1007/ s100380170068.

3. Yamagata K, Tomida C, Umeyama K, Urakami K, Ishizu T, Hirayama K, et al. Prevalence of Japanese dialysis patients with an A-to-G mutation at nucleotide 3243 of the mitochondrial tRNA(Leu(UUR)) gene. Nephrol Dial Transplant. 2000;15:385-8. https://doi.org/10.1093/ndt/15.3.385.

4. Gharavi AG, Kiryluk K, Choi M, Li Y, Hou P, Xie J, et al. Genome-wide association study identifies susceptibility loci for lgA nephropathy. Nat Genet. 2011;43:321-7. https://doi.org/10.1038/ng.787.

5. Yu XQ, Li M, Zhang H, Low HQ, Wei X, Wang JQ, et al. A genome-wide association study in Han Chinese identifies multiple susceptibility loci for lgA nephropathy. Nat Genet. 2011;44:178-82. https://doi.org/10.1038/ng.1047.

6. Kiryluk K, Li Y, Sanna-Cherchi S, Rohanizadegan M, Suzuki H, Eitner F, et al. Geographic differences in genetic susceptibility to IgA nephropathy: GWAS replication study and geospatial risk analysis. PLoS Genet. 2012:8:e1002765. https://doi.org/10.1371/journal.pgen.1002765.

7. Kiryluk K, Li Y, Scolari F, Sanna-Cherchi S, Choi M, Verbitsky M, et al. Discovery of new risk loci for lgA nephropathy implicates genes involved in immunity against intestinal pathogens. Nat Genet. 2014;46:1187-96. https:/doi.org/10. 1038/ng.3118.

8. Trimarchi H, Barratt J, Cattran DC, Cook HT, Coppo R, Haas M, et al. Oxford classification of IgA nephropathy 2016: an update from the IgA nephropathy classification working group. Kidney Int. 2017;91:1014-21. https://doi.org/10. 1016/j.kint.2017.02.003.

9. Yasutake J, Suzuki Y, Suzuki H, Hiura N, Yanagawa H, Makita Y, et al. Novel lectin-independent approach to detect galactose-deficient $\lg A 1$ in $\lg \mathrm{A}$ nephropathy. Nephrol Dial Transplant. 2015;30:1315-21. https://doi.org/10. 1093/ndt/gfv221.

10. Suzuki T, Suzuki T, Wada T, Saigo K, Watanabe K. Taurine as a constituent of mitochondrial tRNAs: new insights into the functions of taurine and human mitochondrial diseases. EMBO J. 2002;21:6581-9. https://doi.org/10.1093/ emboj/cdf656.

11. Wittenhagen LM, Kelley SO. Dimerization of a pathogenic human mitochondria tRNA. Nat Struct Biol. 2002;9:586-90. https://doi.org/10.1038/nsb820.
12. Hotta O, Inoue CN, Miyabayashi S, Furuta T, Takeuchi A, Taguma Y. Clinical and pathologic features of focal segmental glomerulosclerosis with mitochondrial tRNALeu(UUR) gene mutation. Kidney Int. 2001;59:1236-43. https://doi.org/10.1046/j.1523-1755.2001.0590041236.x.

13. Jansen JJ, Maassen JA, van der Woude FJ, Lemmink HA, van den Ouweland JM, t' Hart LM, et al. Mutation in mitochondrial tRNA(Leu(UUR)) gene associated with progressive kidney disease. J Am Soc Nephrol 1997;8:1118-24. https:// www.ncbi.nlm.nih.gov/pubmed/9219161.

14. Yamagata K, Muro K, Usui J, Hagiwara M, Kai H, Arakawa Y, et al. Mitochondrial DNA mutations in focal segmental glomerulosclerosis lesions. J Am Soc Nephrol. 2002;13:1816-23. https://doi.org/10.1097/01.ASN.0000019772.17954 F8.

15. Kobayashi A, Goto Y, Nagata M, Yamaguchi Y. Granular swollen epithelial cells: a histologic and diagnostic marker for mitochondrial nephropathy. Am J Surg Pathol. 2010;34:262-70. https://doi.org/10.1097/PAS.0b013e3181cb4ed3.

16. Imasawa T, Tanaka M, Maruyama N, Kawaguchi T, Yamaguchi Y, Rossignol R, et al. Pathological similarities between low birth weight-related nephropathy and nephropathy associated with mitochondrial cytopathy. Diagn Pathol. 2014;9:181. https://doi.org/10.1186/s13000-014-0181-0.

17. Jennette JC, D'Agati VD, Olson JL, Silva MD, editors. Heptinstall's pathology of the kidney. 7th ed. Philadelphia: Wolters Kluwer; 2015.

18. Cuevas X, Lloveras J, Mir M, Aubia J, Masramon J. Disappearance of mesangial IgA deposits from the kidneys of two donors after transplantation. Transplant Proc. 1987;19:2208-9.

19. Hotta O, Furuta T, Chiba S, Tomioka S, Taguma Y. Regression of IgA nephropathy: a repeat biopsy study. Am J Kidney Dis. 2002;39:493-502. https://doi.org/10.1053/ajkd.2002.31399.

20. Shima Y, Nakanishi K, Kamei K, Togawa H, Nozu K, Tanaka R, et al. Disappearance of glomerular IgA deposits in childhood IgA nephropathy showing diffuse mesangial proliferation after 2 years of combination/ prednisolone therapy. Nephrol Dial Transplant. 2011;26:163-9. https://doi. org/10.1093/ndt/gfq387.

21. Hiki Y, Odani H, Takahashi M, Yasuda Y, Nishimoto A, Iwase H, et al. Mass spectrometry proves under-O-glycosylation of glomerular lgA1 in IgA nephropathy. Kidney Int. 2001;59:1077-85. https://doi.org/10.1046/j.15231755.2001.0590031077.x.

22. Allen AC, Bailey EM, Brenchley PE, Buck KS, Barratt J, Feehally J. Mesangial IgA1 in IgA nephropathy exhibits aberrant O-glycosylation: observations in three patients. Kidney Int. 2001;60:969-73. https://doi.org/10.1046/j.15231755.2001.060003969.x.

23. Itoh A, Iwase H, Takatani T, Nakamura I, Hayashi M, Oba K, et al. Tonsillar $\lg \mathrm{A} 1$ as a possible source of hypoglycosylated $\lg \mathrm{A} 1$ in the serum of $\lg \mathrm{A}$ nephropathy patients. Nephrol Dial Transplant. 2003;18:1108-14. https://doi. org/10.1093/ndt/gfg108.

24. Muto M, Manfroi B, Suzuki H, Joh K, Nagai M, Wakai S, et al. Toll-like receptor 9 stimulation induces aberrant expression of a proliferationinducing ligand by tonsillar germinal center B cells in IgA nephropathy. J Am Soc Nephrol. 2017;28:1227-38. https://doi.org/10.1681/ASN.2016050496.

25. Lowik MM, Hol FA, Steenbergen EJ, Wetzels JF, van den Heuvel LP. Mitochondrial tRNALeu(UUR) mutation in a patient with steroid-resistant nephrotic syndrome and focal segmental glomerulosclerosis. Nephrol Dial Transplant. 2005;20:336-41. https://doi.org/10.1093/ndt/gfh546.

26. Motoda A, Kurashige T, Sugiura T, Nakamura T, Yamawaki T, Arihiro K, et al. A case of MELAS with G13513A mutation presenting with chronic kidney disease long before stroke-like episodes. Rinsho shinkeigaku = Clinical neurology. 2013; 53:446-51. https://doi.org/10.5692/clinicalneurol.53.446.

27. Nishida M, Morimoto M, Ohno K, Hamaoka K. IgA nephropathy in a girl with mitochondrial disease. Pediatr Int. 2015;57:e50-2. https://doi.org/10. 1111/ped.12540.

28. Ayumi I, Yuki N, Yasuaki U, Keiji M, Tetsuya T, Shouichi F. A case of mitochondrial DNA A3243G mutation presenting with renal complications and hearing impairment as the main clinical manifestations. Audiology Japan. 2013;56:769-74. https://doi.org/10.4295/audiology.56.769.

29. Sinniah R. Occurrence of mesangial IgA and IgM deposits in a control necropsy population. J Clin Pathol. 1983;36:276-9.

30. Varis J, Rantala I, Pasternack A. Immunofluorescence of immunoglobulins and complement in kidneys taken at necropsy. J Clin Pathol. 1989;42:12114.

31. Waldherr R, Rambausek M, Duncker WD, Ritz E. Frequency of mesangial IgA deposits in a non-selected autopsy series. Nephrol Dial Transplant. 1989:4: 943-6. https://doi.org/10.1093/ndt/4.11.943. 
32. Sanfilippo F, Croker BP, Bollinger RR. Fate of four cadaveric donor renal allografts with mesangial IgA deposits. Transplantation. 1982;33:370-6.

33. Sugiyama S, Yamamoto T, Tsuyuki M, Ohshima S. Study of IgA nephropathy in the transplanted kidney--sequential changes in mesangial IgA deposits found one hour post-transplantation kidney biopsies. Nihon Jinzo Gakkai Shi. 1986;28:729-37. https://doi.org/10.14842/jpnjnephrol1959.28.729.

34. Suzuki K, Honda K, Tanabe K, Toma H, Nihei H, Yamaguchi Y. Incidence of latent mesangial IgA deposition in renal allograft donors in Japan. Kidney Int. 2003;63:2286-94. https://doi.org/10.1046/j.1523-1755.63.6s.2.x.

Ready to submit your research? Choose BMC and benefit from:

- fast, convenient online submission

- thorough peer review by experienced researchers in your field

- rapid publication on acceptance

- support for research data, including large and complex data types

- gold Open Access which fosters wider collaboration and increased citations

- maximum visibility for your research: over $100 \mathrm{M}$ website views per year

At $\mathrm{BMC}$, research is always in progress.

Learn more biomedcentral.com/submissions 